\title{
A COMPARATIVE STUDY ON TEACHING AND LEARNING CHINESE CHARACTERS BY PRIMARY SCHOOL NON-NATIVE CHINESE LEARNERS IN SOUTH AFRICA AND CHINA
}

\author{
Professor Emeritus NM Nel, \\ Associate Professor S Krog \\ Professor LDM Lebeloane \\ University of South Africa
} Assistant Professor Quan Zhou

Zhejiang International Studies University, China

Given China's fast-growing economy, more people have been motivated to learn Mandarin; however, many encounter challenges in learning the complex characters and consequently abandon it. In view of South Africa's decision to introduce Mandarin as a second additional language in schools (by choice) and China having to cater for non-native Chinese learners in certain schools, the University of South Africa and the Zhejiang International Studies University agreed to embark on a collaborative research project with an emphasis on the teaching and learning of Chinese characters. Qualitative comparative case studies were employed and multiple data collection tools were used, including interviews, questionnaires, lesson observations, and volunteer participant learners and researchers involved in a Chinese characters exercise. A qualitative comparative case study was conducted in order to narrate a cross-unit comparison, comparing and contrasting the findings. Inductive qualitative content analysis of both sets of data (South Africa and China) was done, and three common themes emerged. The data from South Africa and China are discussed individually under the three themes. Common considerations or factors regarding the teaching and learning of Chinese characters are identified, which makes it possible to incorporate them in an eclectic approach (based on lessons learnt by both research parties) in South Africa and China. This comparative study also informs a facilitative process to implement the introduction of Mandarin as a second additional language in South African schools.

Keywords: Chinese characters, non-native Chinese learners, teaching and learning

\section{INTRODUCTION}

Chinese can be considered 'the most difficult major language' due to the great number and complexity of written characters (ShaoLan, 2014: 9), hence '... [aspiring learners] give up mostly because of the characters' (Ren, 2014: 144, 147). Chinese is a unique orthography. Some aspects of Chinese literacy acquisition do not conform with alphabetic orthographies. For example, semantic radicals do not have 'analogy to alphabetic orthographies', which in this case is English. Phonological cues in Chinese are unreliable and word building is reliant on 'lexical compounding', thus morphological awareness is of utmost importance when learning to read. There are also simplified and traditional scripts, and their characteristics, strengths and weaknesses have an impact on the teaching and learning of Chinese. By learning Chinese, segmental and suprasegmental phonological sensitivity and visual skills are promoted, which are cognitive advantages (McBride, 2015: 523). Chinese children are not taught to recognise and to use a phonetic component in a character, yet they are able to do so, which points to a specific relationship between learners' phonological skills and their reading 
(Ho \& Bryant, 1997: 951). Based on the fact that 'phonology is universally involved in reading', a reading disability in Chinese, just like English, can result from phonological deficits (Perfetti, Cao \& Booth, 2013: 11).

There are not many language teachers who have deep insight into the phonetics and phonology of Standard Chinese. In view of the tonal character of Chinese, pronunciation is not receiving the attention needed in Standard Chinese. It is thus necessary that, for the future, Standard Chinese pronunciation should be brought in line with Second Language Acquisition research, so that a 'modern methodology' can be developed that is drawn from findings of research in phonetics and phonology. This necessitates aspects such as teaching materials and training pedagogues (Tř́isková, 2017: 27-28). The Chinese logographic characters are based on meaning instead of phonology. The ability to read the Chinese characters is 'strongly related to a child's writing skills'. Logographic writing in the development of reading is mediated by two mechanisms which interact. The one is orthographic awareness, which facilitates visual symbols, phonology and semantics development. The other is motor programmes, which are established to enable long-term motor memories of Chinese characters to be formed (Tan, Spinks, Eden, Perfetti \& Siok, 2005: 8781). Of great importance in reading Chinese characters is visual skills to enable the person to detect and memorise the stroke patterns required to derive meaning and sound. There are many more stroke patterns that one has to learn and to remember than there are letters in an alphabet. Thus, visual skills are crucial not only in the early stages but also later on when learning to read Chinese (Ho \& Bryant, 1997: 951). Shen (2005: 53) stresses the importance of gaining 'a comprehensive picture of the patterns involved in choosing and using character-learning strategies in classroom learning situations' by non-native learners.

Li (2013: 294-305) explains that learning the Chinese language involves a great deal of practice by learners, including learning by memory and rote-learning strategies. Although classrooms are more participatory and electronic chatrooms are available in this modern age, allowing increased access to real cultural environments, language teachers are unsure of what to teach and how and which 'real world situations' they need to prepare the learners for. Wang and Lai (2015: 93) express their concern that not enough consideration is given to what and how the language (Chinese) should be taught. Furthermore, 'globalization puts pressure on educators to diversify their teaching of language rules and conventions at the microlevel of age, gender, social class, and ethnicity and to teach what the diverse forms mean' (Moeller \& Catalano, 2015: 301).

Wong, Gao, Chai and Chin (2011: 232) found that, by interacting with co-researchers with different backgrounds, experiences and schools, it was possible for them to appreciate each other's perspectives and challenges, ultimately leading to 'mutual understanding, reassurance, and increased confidence in designing/implementing plans' (Wong et al., 2011: 239). The fact that the teaching and learning of Chinese characters is a novel field of research, the authors of this article were motivated to embark on a long-term collaborative research project (between the University of South Africa in South Africa and Zhejiang International Studies University in China) in 2017. The title of the project is: The teaching and learning of Mandarin of nonnative Chinese learners with an emphasis on Chinese characters, which holds common benefits for both parties as it is considered the main reason for non-native Chinese learners of Mandarin to abandon it.

The researchers' current (proactive) research is being conducted in the wake of an agreement between South Africa and China to improve learners' maths, science and technology results. 
This agreement was signed as a step in the direction of improving basic education, and on the basis that education ties can be strengthened on an institutional as well as a policy level. Part of the agreement, which has relevance to our project, is to also promote the Chinese language, the aim being to teach Mandarin in schools in South Africa ('China to help ...', 2016). Subsequently, the South African Department of Basic Education (DBE) listed Mandarin as a second additional language (Grades 4-9) ${ }^{1}$ in the National Curriculum Statement grades $R-12$ (Department of Basic Education, 2015: 3). To expedite and assist with this initiative, the South African Minister of Basic Education, Angie Motshekga, announced that the Chinese government would donate 2000 textbooks to assist local schools which offer Mandarin, as a South African textbook still needs to be developed. In addition, in pilot schools teaching Mandarin, e-learning classrooms would be established ('South Africa formalizing ...', 2016). Further, 100 teachers would be sent to China annually for methodological and cultural enrichment ('SA eyes mass Mandarin teaching...', 2016) and the Chinese government would assist this country in developing a curriculum for teaching Mandarin ('China to help...', 2016).

By embarking on this comparative research, the researchers' common aim is to identify common considerations that can be incorporated into an eclectic approach flowing from the research questions. This is done by drawing a comparison once similarities and differences based on the two sets of findings (South Africa and China) have been identified. In doing so, we will also be contributing to and facilitating the promotion and implementation of Mandarin as a second additional language in South African schools.

\section{APPROACH FOR LEARNING CHINESE CHARACTERS}

Studies have found that learning strategies which non-native learners of Chinese use suggest 'rote memorization, graphic cues and knowledge of radicals' (Shen, 2005: 53). It is necessary to consider how a learner perceives a Chinese character and how the perception develops in order to develop a strategy that is effective to learn Chinese characters. Tse, Marton, Ki and Loh (2007: 384-388) developed an approach based on the 'phenomenographic view of learning and awareness that puts learners' perceptions of what is to be learnt and how these perceptions come about as central to learning.' Thus, a perception-orientated approach was adopted by Tse et al. (2007: 384) 'which integrates enhancement of the way of seeing (perception of the meaning and structures of the language into the process of doing (the reading, writing and the using of language)'. Thus, the way of seeing (i.e., the learner's perception of the meaning and structures of the language) is integrated into the doing process (i.e., reading, writing and using the language).

It is important to highlight the structures of characters (components and how they are put together, what they mean with regard to the meaning/sound of the whole character) where related characters in clusters are present, as well as their similarities and differences. Initially, the meaning and sound of characters must be seen as coming from a context which makes sense to the learner. In this way, the learner focuses on the appearance, sound and context of the characters simultaneously, and discovers that characters and their sounds change as the message in the text becomes clear. The role of the character in the text is stressed, rather than its features. Teaching thus starts with the whole (within context) as it relates to the learner's past experience of the meaning of the words when speaking. In this way, meaningful reading leads to the reader examining how the meanings of the words associate with the characters and their shapes. Emphasis should also be on what the characters mean and how each corresponds to a syllable. The characters and text need to be within the learners' 'mental 
lexicon of meanings' (Tse et al., 2007: 388). Hence, the teacher needs to be instrumental in synchronising the syllables and the position of the characters. To do so would necessitate teachers to acquaint themselves with the types of errors learners are apt to make, to analyse the errors, and how to prevent these errors and support the learners.

In second language acquisition, the aim of error analysis is to identify the errors and the sources of errors a learner makes while acquiring the second language. This process is known as interlanguage (IL). It is assumed that the mother tongue is a solid system, as well as the target language. Moving from the mother tongue to the target language has numerous 'incremental developmental phases/steps/stages/approximations' that are all systematic and governed by developmental rules that are neither $100 \%$ L1-compliant nor $100 \%$ L2compliant, and this is called IL. Thus, those interim grammar rules which the learner relies on for IL performance results in 'systematic performance errors' (Nodoushan, 2018: 63). Error analysis in this day and age has to do with the 'study of error treatment in language teaching' (Nodoushan, 2018: 64), and is thus necessary for future research endeavours as researchers venture deeper into Chinese phonetic learning and related areas.

\section{Research questions}

This study was guided by the following research questions:

1. What are the experiences of primary school non-native Chinese learners learning Chinese characters in the contexts of South Africa and China?

2. What are the experiences of Chinese teachers teaching primary school non-native Chinese learners learning Chinese characters in both contexts?

3. What common considerations or factors can be identified by exploring the experiences of non-native Chinese learners learning Chinese characters and teachers teaching Chinese characters in the two contexts?

4. How can the identified common considerations or factors be incorporated into an eclectic approach for teaching and learning Chinese characters?

\section{RESEARCH METHODOLOGY}

The worldview adopted by the researchers was social constructivism. The researchers explored the subjective meanings of the primary school non-native Chinese learners' experiences of learning Chinese characters in the contexts of South Africa and China. The researchers relied heavily on the views of the participants regarding the learning and teaching of Chinese characters in the two contexts. The subjective meanings and making sense of them were formed by means of interaction with others (the learners, teachers and parents) through discussion or interactions (social constructivism), and the influence of historical and well as cultural norms. The resultant meanings were 'varied and multiple', which led the researchers to 'look for the complexity of views'. Subsequently, a pattern of meaning developed inductively. In so doing, the researchers concentrated on the processes of the participants' interactions with each within their specific contexts, that is, South Africa and China respectively (Creswell, 2007: 20). The participants were active and involved in every phase of the process as they were partners in the whole research exercise (De Vos, Strydom, Fouche \& Delport, 2011: 7). The researchers' own perspectives and appreciating others' perspectives are emphasised in this worldview. Praxis and reflexivity, which is understanding how one's experiences and background affect one's understanding and acts, played an important role in these research efforts (Patton, 2002: 546). 
Qualitative comparative case studies 'for the purpose of cross-unit comparison' (Wilson 2009: 206-207) were used in this study. In a multiple case study such as the present one, 'the researcher replicates the same study' (in South Africa) with different learners (in China) in order to 'compare and contrast the findings' (Efron \& Ravid, 2013: 41-42). Creswell (2007: 74) refers to a 'collective case study', since the subject (teaching and learning Chinese characters) requires multiple case studies from several research sites (South Africa and China). 'Lessons learned' are identified through qualitative synthesis, and generic factors (in this case, the teaching and learning of Chinese characters) are generated that can be used to develop a common approach for teaching Chinese characters to primary school non-native Chinese learners in South Africa and China (Patton, 2002: 500).

Table 1: School contexts and samples ${ }^{2}$

\begin{tabular}{|c|c|}
\hline South Africa & China \\
\hline $\begin{array}{l}\text { School context: a Chinese school (pre- } \\
\text { school to Grade 12) in Gauteng; caters for } \\
\text { all nationalities; language of learning and } \\
\text { teaching is English for non-native Chinese } \\
\text { learners and Mandarin for Chinese learners; } \\
\text { Mandarin is taught on a daily basis (half an } \\
\text { hour) to non-native Chinese learners as a } \\
\text { second additional language. }\end{array}$ & $\begin{array}{l}\text { School context: an international primary } \\
\text { school in Hangzhou for non-Chinese and } \\
\text { overseas ethnic Chinese; Mandarin is taken } \\
\text { as the medium of instruction; learners are } \\
\text { re-grouped according to their Chinese } \\
\text { language competence; a 45-minute } \\
\text { Mandarin class is taught daily as a foreign } \\
\text { language. }\end{array}$ \\
\hline $\begin{array}{l}\text { Sample: convenience sampling - grade } 5 \\
\text { class, } 20 \text { non-Chinese learners. } \\
\text { Criteria used: all these learners started } \\
\text { learning to read and write Chinese } \\
\text { characters in this grade (2017). }\end{array}$ & $\begin{array}{l}\text { Sample: convenience sampling - eight } \\
\text { learners across grades } 1 \text { to } 5 \text { (grading by } \\
\text { Mandarin competence, not age, i.e., grade } 1 \\
\text { is the beginner's level), including both } \\
\text { overseas ethnic Chinese and non-Chinese. } \\
\text { Criteria used: all these learners learn } \\
\text { Mandarin as a foreign/second language. } \\
\text { (Overseas Chinese Mandarin mother-tongue } \\
\text { speakers were excluded from this study - a } \\
\text { significant number of learners.) Difficulties } \\
\text { in accessing large numbers of beginner } \\
\text { Mandarin learners (grade } 1 \text { s) necessitated } \\
\text { sampling across grades. Sample learners } \\
\text { who were not from the beginner group } \\
\text { (grade 1s) shared with the researchers their } \\
\text { experience of when they were beginners. } \\
\text { Chinese cultural background at home does } \\
\text { help those ethnic Chinese non-Mandarin } \\
\text { mother-tongue speakers learning Mandarin } \\
\text { in terms of family support. However, they } \\
\text { still face some challenges similar to their } \\
\text { peers without any Chinese cultural } \\
\text { background at home. As reported by the } \\
\text { teachers interviewed, learners at grade } 1 \text { to } 5 \\
\text { are varied in Mandarin competency, but still } \\
\text { share some similar challenges in learning } \\
\text { Mandarin. }\end{array}$ \\
\hline
\end{tabular}

Per Linguam 2019 35(2):1-17

http://dx.doi.org/10.5785/35-2-846 


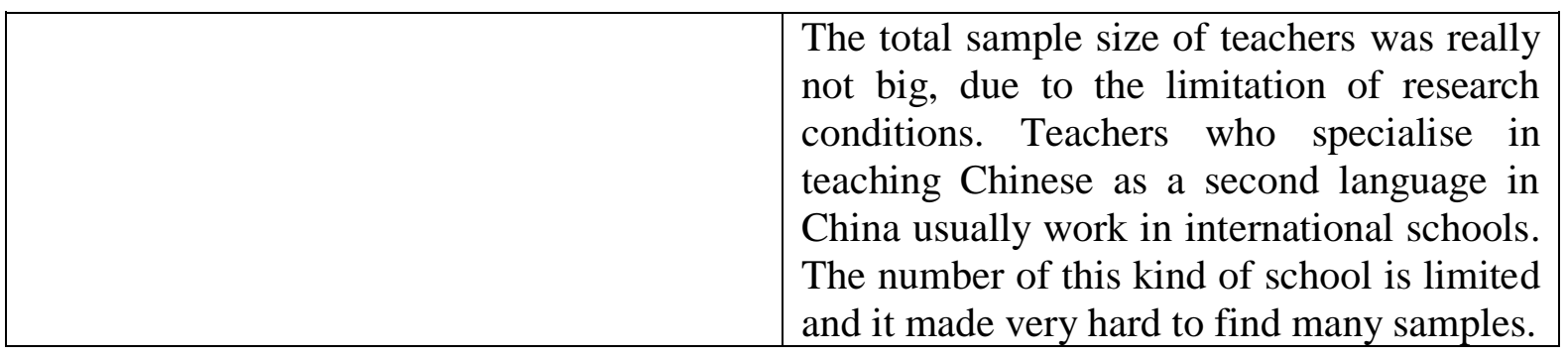

\section{Data collection tools}

Data collection tools developed by the South African team included: a learner focus group interview schedule; individual semi-structured interview schedules for the learners and the principal, deputy principal and teacher; a parent questionnaire (open-ended questions); a learner questionnaire (open-ended questions based on a table consisting of three Pinyin words, the equivalent characters and English words); the teaching lesson presented by learners acting as 'teachers'; and conducting a reflection session after the lesson. The researchers thus used multiple forms of data collection to 'build [an] in-depth case or storied experiences' (Creswell, 2007: 143). In China, the Chinese team adapted the data collection tools to suit their research context. The Chinese side mainly revised the expression of some of its questions and deleted several questions that were not suitable for China's context. By using an 'interpretive lens', the reflexivity of the researchers was emphasised; hence, the researchers reflected on the data collection process and the resulting documented interpretations (Creswell 2007).

\section{Data analysis}

Inductive qualitative content analysis was used in this study, where the themes, patterns, activities and content of the study were organised, described and ultimately compared to arrive at certain causes, consequences and relationships that allow for interpretation (Patton, 2002: 479, 253). Inductive qualitative content analysis depends greatly on the coding process (Elo \& Kyngäs, 2008: 108; Hsieh \& Shannon, 2005: 1285). Content analysis is described as 'the subjective interpretation of the content of text data through the systematic classification process of coding and identifying themes or patterns' (Hsieh \& Shannon, 2005: 1278). Researchers derive themes from the data by immersing themselves in the data (Elo \& Kyngäs, 2008:109-111; Hsieh \& Shannon, 2005: 1279). The researchers categorised the interview transcriptions (conducted by a transcriber) and tabulated these under the emerging themes before recombining them where necessary (Wilson 2009: 209). The interview guides served as 'descriptive analytical framework(s) for analysis' (Patton, 2002: 440). Cross-case analysis was employed, where different participants' answers to common questions were grouped together and 'different perspectives on central issues' (Patton, 2002: 440) were analysed. The additional data gained from the remaining tools were integrated as complementary data under these themes, and were used to cross-check facts and discrepancies. By means of the above multiple

data collection methods, the researchers were able to triangulate the data so that the research findings and conclusions could be strengthened (Wilson, 2009: 209).

\section{FINDINGS AND ANALYSIS}

Per Linguam 2019 35(2):1-17

http://dx.doi.org/10.5785/35-2-846 
Three themes emerged from the interview transcriptions. The categories for each theme will surface as the narrative unfolds. First, the South African data are discussed under each theme heading, then the data from China follow. The themes emerging from China coincided with those from South Africa.

\section{Theme 1}

\section{South Africa: Teacher's Chinese character teaching strategies/teaching styles}

When the teacher was asked how she taught the Chinese characters she explained that she 'show[s] them the Pinyin chart and sound[s] them out to the [learners], then repeat. Then when they are familiar with the sound, we sing it.' The teacher opined that it is important that the learners learn the characters and the Pinyin early in the learning process. This way of teaching was also evident when learners acted as teachers and researchers were taught certain characters and the accompanying Pinyin. The researchers were instructed to repeat the writing of the newly learnt characters and to repeat the sounds until near perfection. In the focus group interview, a learner explained that:

In fact we had a listening skill, so everything for the Pinyin, the character what haven't learned that well, yet. She could like for the beginning she put all the Pinyin in and the characters, for the second one she put a little bit of the characters and a lot of the Pinyin, for the third one she puts barely any Pinyin along with the characters and for the fourth one she put .... It makes it good, either to practice over and over and over, like we get cycles tests and if we do very bad in my cycle test then you have to write more time up, like let's say somebody get 55\%, then they have to everything that they have done wrong, five times. Like if somebody $96 \%$, then they will just have to write it. So they will have to write it.

The teacher first taught the sound, followed by the meaning and finally the characters. In teaching the characters, she taught the strokes and the rules for writing each character, the radicals and associations, by making use of pictures associated with the characters. There was great emphasis on the correct stroke order of the characters, demanding repeated stroke order exercises. The sounds of the characters were first drilled with the use of worksheets and games. One learner explained: 'She puts the computer on, she plays a tape out of a book and then we have to, like, circle the words what we hear. And it is like eight words that you have to circle.' This exercise made the learners aware of the sounds of the characters and matching them with the correct visual form of the character. During a lesson observation, the learners were divided into groups of six to eight and they played a card game, matching characters and pictures as a means to make learning fun but at the same time strengthen the recognition of the characters by sight. All these efforts were part of drill work in order to inculcate the systematic way of learning the characters, both on a visual and an auditory level.

To recognise and write the characters, the teacher used a top-down approach (during our lesson observation) by reading a text and then explaining the meaning. With reference to the phenomenographic theory (Tse et al., 2007: 384-388), it is important how learners perceive the characters. By means of 'guided perceptual experiences' (Tse et al., 2007: 384), the learner's perception of the meaning and structures of the language is integrated into the doing process (i.e., reading, writing and using the language). Emphasis is also placed on the structures of characters, such as related character clusters and their similarities and differences. The meaning and sound of characters come from a context. It is important to note 
that the role of the character is emphasised instead of its features. As the Chinese teacher explained, her teaching started with the whole (context). She also emphasised the meaning of the characters and their correspondence to a syllable. The characters and text need to be within the learners' 'mental lexicon of meanings' (Tse et al., 2007: 388). The teacher thus needs to synchronise the syllables and the characters' positions. Vocabulary and characters were identified in the text, followed by homework (in the form of worksheets) to allow learners to practise the characters. By the end of the year, the learners are expected to construct basic sentences using characters only.

\section{China: Teachers' Chinese character teaching strategies/teaching styles}

All Chinese teachers' teaching strategies are from the arrangement and analysis of interview materials. Teachers' teaching strategies included four parts: how to deal with the greatest challenges in Chinese character teaching, the general procedures of teaching, the specific methods of teaching, and the teaching measures for students' common mistakes.

Chinese language teachers who teach foreigners in China commonly believe that their greatest challenge lies in helping learners combine the character, meaning and pronunciation. In many cases, a learner's reading and writing cannot progress concurrently with his or her listening and speaking skills, as the latter are easier to achieve. To bridge these difficulties, the teachers believe that immersion teaching, which provides a highly supportive target-language environment for Chinese language learners, can offer a solution. Thus, they teach in Chinese. When learners begin their first class, the teachers impart mainly in Chinese (and sometimes in a learner's mother tongue, to assist), before eventually establishing a Chinese-only teaching environment as the learners make progress.

The normal procedures are to teach Pinyin first and then the Chinese characters - a process adopted by most teachers. During the interview, however, one teacher questioned this pattern. She preferred the opposite order of teaching, because she believed it helped learners to read more characters. According to her, it could be challenging for younger non-native learners to start with Pinyin, as its various rules are difficult to memorise, which could make it harder to learn the characters. Younger learners might not be able to read all the letters or words appearing in English texts. Although both English and Pinyin use letters, they are totally different systems. Introducing Pinyin to learners' studies at an earlier stage would thus be likely to confuse them (this was also demonstrated in interviews with learners). Another possible downside of teaching Pinyin before characters is that learners might be more skilled at reading Pinyin than characters, which could be reflected in their ability to listen and speak Chinese well, while showing poor performance in writing.

While teaching the characters, teachers often show them to learners first, before explaining the etymology (often in combination with the relevant traditional Chinese culture, to facilitate understanding) with the aid of pictures. They follow this by asking learners to use their imagination to build their own mnemonic system, and show them how to write the character in the proper order of strokes (which was also an important aspect of learning to write Chinese characters in the South African context) before requiring them to write in the same way. Based on that, teachers may conduct contests around character writing, and assign homework which involves writing practice (Chinese character-writing workbooks). Certain reading materials require learners to read to their parents, and to obtain a parent's signature as evidence of having completed this task. Teachers use various resources to support their teaching, including textbooks, flashcards, information resources and so forth. For example, 
teachers may use online sources such as learning websites and songs on Youku (a popular Chinese online video service similar to YouTube) to support their teaching.

For teaching purposes, teachers usually divide a Chinese character according to its phonetic and semantic parts to help learners remember and understand. It is very challenging for learners to distinguish characters with similar shapes, such as '人 (human)', '入(enter)' and ' 八(eight)'; ‘牛 (cow)' and ‘午 (noon)'. In this case, teachers could tell stories to make it easier to differentiate. For example, to distinguish '酒 (wine)' from '酒 (spill)', teachers may explain as follows: nothing is left after the spill, so the 'bar' is missing (西); brewing wine requires yeast, and the 'bar' (西) represents the yeast. In semantic teaching, teachers may help learners by telling stories according to the components or shape of a character. The most challenging part is explaining function words (in contrast to content words, where learners can use their imagination to help them memorise words). Function words include, for example, '应该 (should)', which requires mechanical memorising and repeated practice. While teaching pronunciation, most teachers encourage learners to memorise by forming an association with the phonetic part of the character. Tones are the most difficult to learn, especially the falling-rising tone and the falling tone, pronunciation of the 'light level' and 'departing' tones. For example, ‘绿 (lǜ)' can possibly be pronounced as ‘吕(lü)'.

\section{Theme 2}

\section{South Africa: Learner learning strategies}

The researchers deemed it useful to ask three selected learners to teach them a few Chinese characters, thereby gaining insight into how the learners learnt the characters. Each learner had 10 minutes to teach the research team a character. Learner A taught the character '人 (rén)' (Pinyin: person/people), learner B introduced the tone signs, and learner C taught the numbers 1 to 10. The first learner started the lesson, and the other two assisted. They wrote the characters on the board, explained the numerical sequence of writing the characters, the pronunciation and the meaning. The researchers were given an opportunity to practise the characters and ask questions. Examples of each of the four tones were written on the board, and the researchers practised the pronunciation. Associations were used to recall the characters, for example, 六(the number 6) looks like a person. Finally, all three learners taught the researchers to write a sentence using the same approach followed above:

- Characters: 來吃早飯.

- Pinyin: lái chī zāo fàn (come eat breakfast).

It was evident that the learners taught the researchers as they had been taught to learn the Chinese characters, that is, with accompanying Pinyin and repetitive exercises.

Responses from the learner questionnaires included: 'I keep practising how to write it then I make up sentences with the character.' 'I practise it over again so I can understand it better.' 'I memorise the characters by writing them over and over again.' I have an extra book where I just keep on practising my characters over and over till I can remember it but if I forget I will ask Lao Shi.' 'I will teach myself the strokes of the character so I could study easier.' 
During classroom observation, the learning environment was learner-friendly, and learners were at ease to approach the teacher, who in turn was responsive to the needs of the learners. Individual learner interviews and focus group interviews reflected positive responses:

I enjoy when [ ] we have to say sentences, she always gives us two characters that we have to say and we either say it loud or soft; It is nicer in a group when you can help each other and we sometimes do words and maybe in groups of 2 or 3; I feel that first you have to learn the Pinyin and then the character because you stop learning the pronunciation first and then you can write the characters. Because you have to learn and to get it right ... the tone, the lines and all of those.

Enjoying the lesson, having the teacher's support and also doing group work, as well as the fact that Pinyin is a way to ease the learners into learning the characters, were factors that enhanced the learning of the characters.

Negative learner responses included: 'When we have to write things over and over.' 'Ja, and also the characters are, like, in here, with the Pinyin you have to learn the tones as well, and those are very confusing.' The teacher noted: 'Reading, I think she is doing much better, but can she understand what she is reading without the English writing below? Writing, yes, she struggles - yes, I think extra support is needed.' The teacher put a great deal of effort into the teaching of the characters. However, there are difficulties which learners and teachers face; hence, there is a need to find ways to overcome these difficulties. The repetitive element which is always present and the four tones, which confuse the learners, exacerbate the difficulty in learning the characters. With reference to the error analysis discussion above, it would be a worthwhile endeavour to get to the root of the difficulties and, in so doing, address them as early as possible.

\section{China: Learner learning strategies}

From the interview, it transpired that learners mainly learnt Chinese in four ways: First, learners learnt through practice, by inventing a story about one specific character. For instance, when learning the character 美(beauty), a learner noted: 'It is composed of a "sheep( 羊)" at the top and a "big(大)" at the bottom. If the sheep is big, she is more beautiful, so she is a beauty.' The learner found a way to recognise and understand the character correctly. Another suggested the teacher 'show me how to use them in [a] sentence', to promote understanding. Second, learners learnt by using pictures as visual stimulation. Learners believed a photo or image would help them understand a character. One learner mentioned learning through photos, by label[ling] items, such as a jar, with its name in Pinyin and Chinese characters both'. Third, learners learnt by emphasising the importance of direct memorisation: 'I will repeat writing the characters until I can memorise them, and my sister will check it for me.' 'I have homework writing Chinese characters. It helps in memorisation because it makes me write repeatedly.' 'We have copies to make and will look them up in the dictionary back home, so it helps to consolidate the memory.' In the process of writing characters repeatedly, strokes and radicals played an important role: 'I write them in radicals, and the radicals help to memorise.' Finally, learners learnt by highlighting the significant influence of the mother tongue on Chinese learning. As one participant noted: "My Chinese name "Mei" and English name "May" all start with an "M". They are both my names. They are connected.' 
It appears that there were similarities in the way the non-Chinese learners in China learnt the Chinese characters, for example, the use of visual aids and writing the characters repeatedly. As explained earlier, ethnic Chinese non-Mandarin mother-tongue speakers learning Mandarin who have a Chinese cultural background at home have an advantage in terms of family support. However, they are still faced with challenges which are similar to those of their peers who do not have a Chinese cultural home background. The influence of interlanguage, where the learner is reliant on the L1 grammar rules, leads to 'systematic performance errors' (Nodoushan 2018: 63), which applies to both sets of learners and which calls for error treatment in Mandarin teaching.

In the process of learning, learners preferred to write characters beautifully. They explored the fun of learning Chinese and enjoyed the contests their teachers arranged. One learner said: ' $I$ will write Chinese characters prettier than others, because my name (Meimei) means "beauty".' In mentioning handwriting, some learners described the process as 'painting' because the characters look beautiful. One learner said it was funny how stories came to his mind about the characters once he saw them. One of the amazing things about Chinese characters is that they intrigue learners to learn: "The characters are interesting, like "奇 (strange)". It can be combined with “1/人 (human)” as “倚 (lean)” or with “马 (horse)” as “骑 (ride)". I think it very interesting that the teacher teaches us more characters through the combinations. I am impressed.' Learners also loved the contests, which had same results as game-playing, to make teaching more effective. 'I love the contests of character writing. Like the teacher asks us to find the phrase “害怕(scared).” Whoever finds it first, [gets] a point.' 'I love the competition to find out who can write faster than others or has the best handwriting.'

Most learners did not like to write characters repeatedly: 'I don't like too much writing. My arm gets sore if I write too much.' 'Writing Chinese wears me down faster than writing English.' They also did not enjoy tests aimed at evaluating teaching performance: 'I don't like the test, but I enjoy the lesson.' Some participants mentioned that they did not want to be the one whose handwriting was not pretty, nor to be laughed at by others. There are many similarities between English letters and Pinyin, which can confuse learners: 'I can't tell the difference. They look [the] same to me (especially to beginners).' 'I couldn't tell when I was [in] grade one and two.'

\section{Theme 3}

\section{South Africa: Parental roles/involvement}

Generally, parents were very supportive of their children learning Mandarin, hence their decision to enrol them in a Chinese school. One parent stated: 'We were apprehensive at first. The progress since last year has, however, shown that the learning of the language is not as difficult as we had anticipated.' Another parent explained:

Progress can be observed on a long-term, not on a day-to-day basis. The reading and writing of Chinese characters keeps him motivated and looking ahead to the next day's class. My child enjoys learning the Chinese characters as he finds them more interesting than the English. 
Parental involvement in terms of learning the Chinese characters can mainly be related to homework, communication with the school and their children's progress. A parent stated: 'I hardly interact with the teacher. Feedback is normally through her school report or parents' evening. I check her homework.' Another said: 'I have not seen the reason to communicate with the teacher because I have not seen any need to; my son is doing quite well in the language and he enjoys it very much.' In response to a question about them learning Mandarin, one parent said: 'Yes, we are encouraged, but simply do not have time to do so. Also classes are on Saturdays and clash with other commitments.' Another said: 'No, Mandarin adult classes are offered independently and at a cost.' A learner responded by saying: 'My dad, he is quite good at Chinese so he also helps me sometimes. He sometimes takes, like, online classes to learn.' With regard to parents' knowledge of their children's progress, one parent said: 'She has enjoyed learning the language, however she has and continues to struggle with writing the characters - particularly the tone signs.' Another parent noted: 'There's certainly progress, in the time he takes to complete his tasks and the comfort he does it with. He enjoys it and always has fun writing the characters and learning new things every day.'

Generally, the parents were pleased with the fact that their children were learning Chinese characters and the progress they made. Although the parents were not familiar with the language and were not able to communicate in Mandarin, they encouraged their children and pointed out the benefits of learning the language. Parents were not confident in helping their children with their Mandarin homework and were dependent on the teaching the children received during school time.

\section{China: Parental roles/involvement}

Parents showed their support of their children learning the Chinese language. Some of them made their own choice to send their children to study the Chinese language. They were highly motivated to find ways to improve their children's Chinese language proficiency and to teach them about the Chinese culture.

As regards homework, parent-child reading, parent-teacher meetings and communication with teachers, parents were very involved in their children's Chinese language learning. Some parents chose to contact the teacher via WeChat or other social networks to be updated on their children's progress. A parent shared her joy with the teacher regarding her child's progress:

He just told us in both Chinese and English the story of 'General Tian Ji in a horse race (田忌赛马)' [a famous anecdote of ancient China]). He also challenged his father about how to win the race. It was a well done. We were proud of him and he said that he 'enjoyed the Chinese lesson today.'

Another parent expressed his gratitude towards the teacher: 'She is so happy with Chinese and tells me it is her favourite thing about school. Thanks for all you do for her. She gets so excited when you message her.' Some parents who could speak Chinese tutored their children at home. One learner mentioned that his father would teach him Chinese characters by telling stories, and he loved it.

\section{CONCLUSION}

Per Linguam 2019 35(2):1-17

http://dx.doi.org/10.5785/35-2-846 
The authors of this article were able to provide evidence in the findings section for the research questions pertaining to the experiences of the teachers and learners of Chinese characters in South Africa and China. Common factors were identified in both contexts regarding the teaching and learning of Chinese characters. These factors are considered as the authors arrive at an eclectic approach, influenced by the phenomenographic view and substantiated by literature.

In the South African context, all the participant learners indicated that they enjoyed learning Mandarin, the way they were taught and supported by the teacher, and the group activities. This was reflected in the way that the learners taught the researchers selected characters. It was also evident that learners were intrinsically motivated to strive for excellence as they practised writing the characters over and over in an effort to memorise and perfect the characters. The importance of learning the characters accompanied by Pinyin was also expressed by the learners as part of the character learning process. The general challenges the learners experienced were writing the characters repetitively and having to simultaneously learn the Pinyin and its tones (which are confusing). The teacher was concerned about the learners' understanding of what they read without having accompanying English text. This necessitates extra support.

The main aim of the Chinese teacher in the South African school under study, in teaching Mandarin, was for learners to be able to engage in everyday communication, and to be able to write sentences using only characters. Liu (2002: v-vi) claims that Chinese language teachers are leaning more towards developing learners' communicative ability in Mandarin; therefore, teaching materials should be learner-centred. The South African Chinese teacher was in favour of first teaching the sounds, then the meaning, and lastly, the strokes and rules of writing the characters. This she did using pictures, worksheets, games, tapes and computers. Using a top-down approach, she read the text, explained the meaning, and learners identified vocabulary and characters. Ultimately, the learners had to be able to write sentences by the end of the year.

The parents were in favour of their children learning Mandarin, and were pleased that their children enjoyed learning Mandarin and with their children's progress. However, some parents reported that their children found it difficult to learn the characters. Parents tried to be involved in their children's learning, but were met with numerous challenges. Although learners were expected to do homework, parents expressed that they did not have the time to help their children and that they were unable to attend Mandarin classes on Saturdays due to other commitments. The most positive and significant outcome expressed by the parents was their children's enjoyment of learning the characters.

In the context of China, most learners were motivated to learn, with their enthusiasm being closely related to the teaching methods their teacher adopted. Learners cared about beautiful handwriting, discovering the charm of the Chinese language and participating in contests during their study. Among their least favourite activities were too much writing, not having beautiful handwriting and being made fun of by their peers. Chinese characters were viewed varyingly: some learners believed in Pinyin, while others confused it with the English alphabet. Some learners used their mother tongue to help them recall the characters and most enjoyed participating in classroom contests. Teachers usually started with Pinyin, then the characters. Helping learners to learn the characters, their meaning and pronunciation was a significant challenge. Most teachers adopted different teaching methods and used diverse 
teaching resources to support their teaching. Of all the classroom activities, games and contests were the most effective ways of motivating learners to learn.

The main aims of Chinese language teachers in international schools in China were (along with the study of Chinese language knowledge and skills) further clarifying study goals, cultivating autonomous and collaborative study, and forming an effective study strategy so as to be able to use the language in a comprehensive way. For beginners, they adopted the HSK (Chinese proficiency test organised by the Confucius Institute Headquarters in China) level standard. They prepared learners to be able to use simple Chinese words as well as sentences, to also understand them when communicating and even to go beyond that. The order of learning the Pinyin before learning the characters was widely adopted. In the process of teaching, teachers used various teaching resources, photos, flashcards, textbook, games or activities, and information resources as teaching aids. Through immersion teaching, learners entered an environment which provided them with numerous opportunities to practise their listening, speaking and writing skills, which would improve their Chinese language competence in a comprehensive way. Parents strongly encouraged their children to study the Chinese language, and they were involved in the process through checking homework, undertaking parent-child reading, attending teacher-parent meetings and communicating with the teacher. They hoped their children would master the language. If one parent in a family was fluent in Chinese, he or she tended to tutor the child at home.

The approaches used by the South African and Chinese teachers in this study were much along the lines of Tse et al. (2007: 375), who developed an approach based on the phenomenographic approach to learning together with other ways to teach Chinese characters. The learners start learning with their own language, and the characters are introduced to the learners to use in meaningful contexts. Systematically, the structural features of the characters, the written form and the pronunciation are attended to. The learners and teachers in both contexts reported sharing good experiences and similar challenges. The difference is that South African learners were not immersed in the language, and hence did not have the advantage of being exposed to Chinese as frequently. The most significant aspect in both contexts was the enjoyment of learning the characters by way of fun activities and effective teaching and learning strategies.

For Chinese learners, the most commonly employed strategies were related to memory and rote learning. For South African learners, memory strategies, repetitive practice and orthographic knowledge-based strategies (e.g., analysing the character by applying learned orthographic knowledge - knowledge of radicals and formation of characters), and metacognitive strategies (analysing one's own character learning processes and results) were employed for writing characters and reading aloud with Pinyin. When teaching characters to young learners, the focus should be on the 214 basic radicals. Picture methods are best for teaching characters. It is vital to deal with learners' schema conflict appropriately (e.g., cultural and language differences), as their alphabetic language background presents difficulties with Chinese as an ideographic language. Learners need to learn to speak Chinese using a thematic format. Learning to read and write Chinese characters involves moving from the most basic to the more complex, from characters with fewer strokes to those with more strokes (Li, 2013: 66-75).

Regarding the implementation of Mandarin as a second additional language in South African schools, it is necessary to develop textbooks for the South African context in conjunction with Chinese language experts. It is, however, a prerequisite that there be an adequate syllabus and 
that research be conducted on how South African learners process Mandarin acquisition. According to Burhansyab (2019: 71), earlier studies have found that most of the errors L2 learners make are due to interlingual factors. Findings by Lan (2019: 437) regarding L1 transfer errors from English to Chinese have contributed significantly to theoretical as well as pedagogical aspects. The focus was on common types of errors in Chinese writing by Chinese L2 learners as a result of English influences. Since language transfer, negative language transfer and error analysis theories are relevant to second language acquisition research, it is important to include the identification of errors which result from negative language transfer (Yang 2019: 603). This calls for a holistic plan to develop Mandarin teaching and a national body to coordinate and integrate the efforts of various individuals and organisations (Zhang \& $\mathrm{Li}, 2010: 96)$. Therefore, this collaborative project will continue as a sequel to this article as we investigate the influencing factors in Chinese phonetics learning.

\section{END NOTES}

${ }^{1}$ The three-curricula model for language learning and teaching: 1. 'Home language' as first language (as well as language of learning and teaching). 2. 'First additional language' as a second language. 3. 'Second additional language' as an optional third language, e.g., Mandarin (English Second Additional Language, 2002:4).

${ }^{2}$ There are some differences between the two groups. Of course, learning Chinese in China will be a better language context, but there are still similar difficulties teachers and learners will face, since they are all non-native Chinese. The length of tuition time may make it easier to solve these problems, but it won't make them disappear. Although the teachers in the two countries adopt different ways to solve these difficulties, there are still many similarities. Comparing and finding the similarities and differences, we identified the general teaching strategies used in the two contexts, which was the main purpose of this research, hence these discrepancies will not influence research outcomes.

\section{REFERENCES}

BURHANSYAH, B. 2019. Analysis of error sources in L2 written English by Indonesian undergraduate students. Studies in English Language and Education, 6(1):71-83. DOI: https://doi.org/10.24815/siele.v6i1.6659

China to help South Africa improve education. 2014. Available from http://search.proquest.com/docview.1512411034?accountid=14648 [Accessed: 29 April 2016].

CRESWELL, JW. 2007. Qualitative inquiry \& research design: choosing among five approaches. Thousand Oaks, CA: Sage.

DEPARTMENT OF BASIC EDUCATION. 2015. Republic of South Africa. Regulation Gazette No. 10396. Government Gazette, 597(38589):1-8.

DE VOS, AS, H STRYDOM, CB FOUCHE \& CSL DELPORT. 2011. Research at grass roots (4th ed.). Pretoria: Van Schaik.

EFRON, SE \& R RAVID. 2013. Action research in education: a practical guide. London: Guilford.

ENGLISH SECOND ADDITIONAL LANGUAGE. 2002. Revised National Curriculum Statement grades R-9 (schools). Languages: English - second additional language. Government Gazette, 443(23406), May. 
ELO, S \& H KYNGÄS. 2008. The qualitative content analysis process. Journal of Advanced Nursing, 62(1):107-115. DOI: https://doi.org/10.1111/j.1365-2648.2007.04569.x

HO, CS \& P BRYANT. 1997. Phonological skills are important in learning to read Chinese. Developmental Psychology, 33(6):946-951.

HSIEH, H \& SE SHANNON. 2005. Three approaches to qualitative content analysis. Qualitative Health Research, 15(9):1277-1288. DOI: https://doi.org10.1177/1049732305276687

LAN, Y. 2019. Interlingual interfaces in Chinese language learning and its use: exploring language transfer errors in Chinese writing. Journal of Language Teaching and Research, 10(3):437-445. DOI: https://doi.org/10.17507/jltr.1003.05

LI, L. 2013. The teaching and learning of Chinese in English primary schools: five exploratory case studies in the West Midlands region of the UK. Unpublished $\mathrm{PhD}$ thesis, University of Warwick, United Kingdom.

LIU, X. 2002. New practical Chinese reader. NOTCFL. China: Beijing Language \& Culture University Press.

MCBRIDE, CA. 2015. Is Chinese special? Four aspects of Chinese literacy acquisition that might distinguish learning Chinese from learning alphabetic orthographies. Educational Psychology Review, 28(3):523-549.

MOELLER, AK. \& T. CATALANO. 2015. Foreign language teaching and learning. In International encyclopaedia of the social \& behavioral sciences (2nd ed.) (Vol. 9). S.1.: s.n. 327-332. Lincoln: Elsevier BV.

NODOUSHAN, MAS. 2018. Toward a taxonomy of errors in Iranian EFL learners' basiclevel writing. International Journal of Language Studies, 12(1):61-78.

PATTON, MQ. 2002. Qualitative research \& evaluation methods. London: Sage.

PERFETTI, C, F CAO \& J BOOTH. 2013. Specialization and universals in the development of reading skill: how Chinese research informs a universal science of reading. Scientific Studies of Reading, 17:5-21. DOI: https://doi.org/10.1080/10888438.2012.689786

REN, X. 2014. Character teaching in TCFL in the English context: dilemma and breakthrough, a discussion based on the perspective of semiotics. Comparative Literature, 1:12.

SA eyes mass Mandarin teaching in schools in five years - Minister. 2016. Available from: http://www.chinese-embassy.org.za/eng/zngx/whjl/t1357520.htm [Accessed: 28 April 2016].

South Africa formalising Mandarin teaching - Minister. 2016. Available from: http://www.chinadaily.com.cn/world/2016-03/08/content_23779929.htm [Accessed: 28 April 2016].

SHAOLAN, H. 2014. Chineasy: the new way to read Chinese. London: Thames \& Hudson Ltd.

SHEN, HH. 2005. An investigation of Chinese-character learning strategies among nonnative speakers of Chinese. System, 33:49-68.

TŘÍSKOVÁ, H. 2017. Acquiring and teaching Chinese pronunciation. Explorations into Chinese as a Second Language, 31. DOI: https://doi.org/10.1007/978-3-319-54027-6_1

TSE, SK, F MARTON, WW KI \& EKY LOH. 2007. An integrative perceptual approach for teaching Chinese characters. Instructional Science, 35:375-406.

TAN, LH, JA SPINKS, GF EDEN, CA PERFETTI \& WT SIOK. 2005. Reading depends on writing, in Chinese. PNAS, 102(24):8781-8785.

WANG, R \& L LAI. 2015. Intercultural language teaching and learning, by A.J. Liddicoate and A. Scarino. Language and Education, 29(1):93-96.

WILSON, E. 2009. School-based research: a guide for education students. London: Sage. 
WONG, LH, P GAO, SC CHING \& CK CHIN. 2011. Where research, practice and the authority meet: a collaborative inquiry for development of technology-enhanced Chinese language curricula. The Turkish Online Journal of Educational Technology, $10(1): 232-243$.

YANG, X. 2019. A review of negative language transfer regarding the errors in English writing in Chinese colleges. Journal of Language Teaching and Research, 10(3):603609. DOI: https://doi.org/10.0rg/10.17507/jltr.1003.24

ZHANG, GX \& LM LI. 2010. Chinese language teaching in the UK: present and future. Language Learning Journal, 38(1):87-97.

\section{BIOGRAPHICAL NOTES}

Norma Nel is a professor emeritus and research fellow (NRF rated) in the Department of Psychology of Education, College of Education at UNISA. Her responsibilities include postgraduate supervision, research and team leader of an international collaborative research project. She serves as editor for international journals and on international conference committees.

Quan Zhou is an assistant professor in the Department of Education, School of Education at Zhejiang International Studies University. His responsibilities include deputy head of department, undergraduate tutor. His research areas include philosophy of education and culture of fear in education.

Soezin Krog, an associate Professor, in the Department of Early Childhood Education and Development, College of Education at the University of South Africa. She holds a D ED. She has supervised Masters and Doctoral students. She is currently involved in research related to education on a national and international level. Her fields of specialisation are: Early Childhood Education, Physical Education, sports coaching and sport psychology.

LDM Oupa Lebeloane, full Professor, Department of Science and Technology, College of Education at UNISA. He holds a DEd. He's been Chair of Department, School Director and Acting Dean. He's supervised Masters' and Doctoral students. His research focus includes Didactics, Educational Leadership, Environmental Education and Management, Language Education. He serves on editorial board of an international journal and conference committees. 